\title{
Scripta
}

\section{Cinc edicions del Venturós Pelegrí a la Bibliothèque Mazarine de París}

\section{Five editions of the Venturós Pelegtí in the Bibliothèque Mazarine in Paris}

\author{
John Mahiques Climent \\ jomahiques@yahoo.es
}

Universitat de Barcelona

\begin{abstract}
Resum: El ms. 4504 de Bibliothèque Mazarine de París aplega, per una banda, cinc exemplars impresos de la «Peregrinació del Venturós Pelegrí» ab les «Cobles de la Mor丸» i, per altra banda, una còpia manuscrita parcial del Venturós Pelegrí amb una traducció francesa incompleta a cura de Josep Tastu (1787-1849), que s'encarregà de compilar tots els materials del volum. A banda de presentar el contingut general del ms. 4504, descrivim amb detall cada una de les cinc edicions, posant especial èmfasi en la més antiga, probablement datada de mitjan segle XVI o poc després. Pel fet d'ésser el testimoni més antic que coneixem del Venturós Pelegrí, aquest exemplar acèfal i àpode, estampat a línia seguida amb tres gravats encara visibles, aporta dades rellevants per al coneixement de les vies de difusió d'aquesta obra als segles XVI-XVII.
\end{abstract}

Paraules clau: Edad Moderna, Poesia catalana, Impremta, Xilografia, Josep Tastu.

\begin{abstract}
The Ms. 4504 of the Bibliothèque Mazarine in Paris contains, on the one hand, five printed copies of the "Peregrinació del Venturós Pelegrí» ab les "Cobles de la MorA» and, on the other hand, a partial hand-written copy of the Venturós Pelegrí with an incomplete French translation by Josep Tastu (1787-1849), who compiled all the materials of this volume. Apart from presenting the general content of the ms. 4504, we describe in detail the five editions with particular emphasis on the oldest one, probably dating from the mid-sixteenth century or shortly thereafter. This printed book, now acephalous and apodous, in which the lines go all the way across the page, still preserves three woodcuts. As the earliest witness we know of the Venturós Pelegrí, this printed copy provides some evidences to understand the dissemination of this work during the sixteenth and seventeenth centuries.
\end{abstract}

Keywords: Modern Age, Catalan poetry, Printing, Woodcut, Josep Tastu.

DATA PRESENTACIÓ: 16/04/2015 ACCEPTACIÓ: 18/05/2015 • PUBLICACIÓ: 12/06/2015

SCRIPTA, Revista internacional de literatura i cultura medieval i moderna, núm. 5 / juny 2015 / pp. 122 - 138 ISSN: $2340-4841 \cdot$ doi:10.7203/SCRIPTA.5.6378 


\section{Introducció}

El ms. 4504 de la Bibliothèque Mazarine de París és en realitat una col lecció factícia que, en la seua major part, aplega diversos exemplars impresos de la «Peregrinació del Venturós Pelegrí» ab les "Cobles de la Mort), dues obretes que foren utilitzades com a materials pedagògics per aprendre les primeres lletres, probablement des del segle XVI, quan comencem a documentar les primeres notícies sobre la seua difusió conjunta (Verrié 1981: 21-28; Mahiques 2016a). Tot i així, la primera edició datada que ens ha arribat és força posterior, de l'any $1635 .{ }^{1}$ Sotmeses a diferents privatives o privilegis circumscrits a la Catalunya dels segles XVII-XVIII, primer a càrrec de la Confraria de Llibreters de Barcelona anomenada de Sant Jeroni, i després a càrrec de la Universitat de Cervera, ambdues obres es difongueren generalment en un petit plec solt compaginat a partir de tres fulls, cada un dels quals estaria format per vuit folis degudament plegats. ${ }^{2}$ Els tres quaderns estarien inserits el tercer a dins del segon, i aquests dos a dins del primer (Mahiques 2014: 189-190).

El volum parisenc es pot dividir en dues parts diferents: per una banda, cinc exemplars impresos (tres acèfals i àpodes, més dos complets) que, tal com ens han arribat, no tenen cap data concreta, tot i que s'haurien de situar aproximadament entre la segona meitat del segle XVI i l'inici del Vuitcents; i per altra banda, una còpia manuscrita que inclou una transcripció parcial del text català més una traducció francesa incompleta, realitzada per Josep Tastu (1787-1849), a qui hem d'atribuir l'esforç de copiar aquesta part i de recopilar les edicions contingudes en el ms. 4504. A jutjar pels materials reunits en aquest volum, no hi ha cap mena de dubte que Josep Tastu planificà una edició del Venturós, i no només del text català sinó també de la traducció que ell mateix inicià i deixà a mig fer. Aquesta empresa seria, doncs, una de les diverses iniciatives inacabades de l'eminent bibliògraf. ${ }^{3}$

1 A partir d'ara ens referirem també a aquestes obres a través de les formes abreujades Venturós Pelegrí, Venturós, Pelegrí i Cobles. Aquest article ha estat redactat en el marc de la 37a borsa d'estudis Ramon d'AlòsMoner, concedida per l'Institut d'Estudis Catalans en la convocatòria de l'any 2014, tot aprofitant materials aplegats prèviament durant una estada postdoctoral a l'Institut National d'Histoire de l'Art de París; i s'integra igualment en una de les línies desenvolupades al Grup de Recerca Consolidat «Pragmàtica de la Literatura a l'Edat Mitjana» (AGAUR, 2014SGR51) de la Universitat de Barcelona.

2 Una reforma de les ordenances del gremi de llibreters de Barcelona, introduïda el 1623, atorgà a aquesta corporació el monopoli sobre el Pelegrí i moltes altres obres que podrien adscriure's a la literatura de canya i cordill, com el Llibre de bons amonestaments d'Anselm Turmeda; a partir del 1718, en virtut d'un privilegi reial que s'aniria concretant a través d'altres disposicions posteriors, aquests mateixos drets passaren a la Universitat de Cervera. Aquests aspectes legals han estat ben estudiats per Burgos Rincón (1997), en el qual es fonamenten en bona mesura les visions panoràmiques que exposem sota Mahiques (2015b; 2015c).

3 Tampoc va reeixir el projecte d'editar la poesia de Joan Pujol i, encara així, les aportacions de Josep Tastu són també de primer ordre per estudiar l'obra d'aquest poeta mataroní, ja que el ms. 4495 de la Bibliothèque Mazarine és acèfal i dels folis perduts només conservem la transcripció d’una edició seua, no enllestida, de la qual a penes s'imprimiren uns pocs exemplars. Nosaltres n'hem consultat un de custodiat a la Bibliothèque de la Sorbonne, [RRA 8=681], provinent de la biblioteca d'Alfred Morel-Fatio. A l'esmentada edició, el text

SCRIPTA, Revista internacional de literatura i cultura medieval i moderna, núm. 5 / juny 2015 / pp. 122 - 138 ISSN: 2340-4841 $\cdot$ doi:10.7203/SCRIPTA.5.6378 
Ara bé, com de seguida veurem, l'esforç esmerçat per aquest estudiós no fou inútil, ja que aquests materials constitueixen una font de primer ordre no només per estudiar la transmissió del Pelegrí i les Cobles sinó també per realizar una edició crítica d’aquestes obres.

\section{Descripció externa del ms. 4504 i contextualització històrica dels impresos que conté}

Tal com es pot comprovar a la descripció que nosaltres mateixos hem incorporat a MCEM (2014, ID1324), el ms. 4504 de la Bibliothèque Mazarine de París ha estat enquadernat en mitja relligadura, segons un format que és comú a una bona part dels manuscrits que formen el llegat Tastu d'aquesta institució. ${ }^{4}$ És de petites dimensions, amb cobertes dures i una relligadura molt ben travada que en dificulta l'obertura. La major part dels folis mesuren $147 \times 100 \mathrm{~mm}$, però els ff. 56-60 fan aproximadament $400 \times 125 \mathrm{~mm}$, i els ff. $61-69$ uns $200 \times 125 \mathrm{~mm}$. A la part superior del llom, podem llegir: «VENTUROS | PELEGRI»; i a la part inferior: «BIBLIOTHEQUE | MAZARINE». Hi ha quatre folis de guarda a l'inici i altres quatre al final, mentre que el cos del volum, amb numeració discontínua, està format pels ff. [1]-116. A la quarta guarda es veu un segell que indica: «BIBLIOTHÈQUE MAZARINE. DON 28431».

Tot seguit analitzarem de manera individual i detallada els cinc impresos aplegats en aquesta col lecció factícia, però abans els presentarem en el seu conjunt a través d'una taula que inclou les dades més rellevants. El volum que estem estudiant reuneix cinc edicions diferents de la Peregrinació del venturós pelegrí n'ocupen els ff. [1-54] tres d'acèfales i àpodes. Segueixen a aquests tres exemplars un grup de fulls manuscrits, concretament els ff. 55-69. A continuació, hi ha dues edicions setcentistes conservades íntegrament, degudes, segons el peu d'impremta, a Emmanuel / Manuel Ibarra durant la seua etapa cerverina. ${ }^{5}$

no va precedit de cap portada, i comença amb la transcripció del poema sobre la batalla de Lepant, de la qual cosa es dedueix que, quan Tastu posseí el manuscrit, no era acèfal. Comentem aquest aspecte amb més detall sota MCEM (2014, ID 1322). Remetem, igualment, a Mahiques (2013).

4 A banda de MCEM, vegeu Molinier (1892-1898: 329), Massó i Torrents (1902: 143) i Pagès (1888: 176-177, núm. VIII).

5 Tal com hem indicat, el volum ha estat foliat de manera discontínua. Els ff. 70-116 abracen en total 48 ff., no 47, raó per la qual hem indicat la foliació de e tot afegint un guarisme amb superíndex ( $\left.93^{\mathrm{bis}}\right)$. Al final de l'article es pot consultar el llistat de les edicions que esmentem a través de sigles, que marquem en negreta.

SCRIPTA, Revista internacional de literatura i cultura medieval i moderna, núm. 5 / juny 2015 / pp. 122 - 138 ISSN: $2340-4841 \cdot$ doi:10.7203/SCRIPTA.5.6378 


\begin{tabular}{|c|c|c|c|c|}
\hline Sigla & $\begin{array}{c}\text { Folis que } \\
\text { ocupa al ms. } \\
\mathbf{4 5 0 4}\end{array}$ & $\begin{array}{c}\text { Estat de } \\
\text { conservació }\end{array}$ & Lloc i impressor & Data \\
\hline$a$ & {$[1-22]$} & acèfal i àpode & [Cervera: Universitat de Cervera] & $\begin{array}{c}\text { [s. XVIII o inici del s. } \\
\text { XIX] }\end{array}$ \\
\hline$b$ & {$[23-40]$} & acèfal i àpode & $\begin{array}{c}\text { [¿Cervera: Manuel Ibarra?; o bé: } \\
\text { ¿Girona: Impremta de Bro o } \\
\text { successors?] }\end{array}$ & $\begin{array}{c}\text { [s. XVIII o inici del s. } \\
\text { XIX] }\end{array}$ \\
\hline$c$ & {$[41-54]$} & acèfal i àpode & [desconeguts] & {$[2$ meitat s. XVI?] } \\
\hline$d$ & $70-[93]$ & complet & Cervera: Emmanuel Ibarra & {$[1735-1757]$} \\
\hline$e$ & {$\left[93^{\text {bis }}+[94]-\right.$} & complet & Cervera: Manuel Ibarra & {$[1735-1757]$} \\
\hline
\end{tabular}

Tot i la distinció entre Manuel / Emmanuel Ibarra, o altres variants gràfiques molt similars, aquests noms es refereixen a un únic impressor, natural de Saragossa, que treballà a Cervera des de 1735 fins a la data de la seua mort el 1757, amb l'excepció dels anys 1749-1754 en què es traslladà temporalment a Madrid (Llanas 2003: 189-190). Segons aquestes dades, almenys dues de les edicions que ara ens ocupen deurien haver sortit entre els anys 1735-1749 i 1754-1757. Les tres primeres, és a dir $a, b$ i $c$, són incompletes i només se'ns han conservat en aquest manuscrit de la Bibliothèque Mazarine.

Per una banda, el fet que $a$ aprofite les mateixes matrius que una edició cerverina no datada (PVC1) ens fa suposar que ben probablement ambdós volumets foren estampats al mateix taller. Per altra banda, la plausible adscripció de $b$ al susdit tipògraf saragossà es fonamenta en la sèrie de gravats que aquesta edició reprodueix, car és exactament la mateixa que trobem en un altre volum signat per Emanuel Ibarra (PVC2). De tota manera, tal com exposem a Mahiques (2016b), les mateixes planxes foren reutilitzades en un imprès sine notis que creiem sorgit a Girona al final del s. XVIII o a l'inici de la centúria següent $(P V G)$, per la qual cosa no es pot descartar completament que $b$ fos igualment una edició gironina. Dit altrament, $b$ podria adscriure's a Cervera o Girona perquè les mateixes xilografies il lustren altres llibres publicats en aquestes dues ciutats.

El cas més problemàtic recau sobre $c$, que és sens dubte l'edició més antiga de totes les aplegades al ms. 4504. Un dels seus trets més notables és el fet de disposar els versos a línia seguida, com totes les edicions mallorquines dels segles XVII-XVIII que ens han arribat, però es distingeix d'aquestes pel fet d'incorporar les Cobles de la Mort.

Degut a la seua conservació en estat fragmentari, desconeixem si $a, b$ i $c$ inclö̈en alguna indicació de lloc, impressor o data. En canvi, $d$ i $e$ s'han conservat íntegrament en aquest volum i tenen en comú el fet de presentar xilografies documentades a la Barcelona del Setcents, tal com hem estudiat a Mahiques (2015c). Concretament, $d$ utilitza materials gràfics parcialment estampats per Rafel 
Figueró (PV1714), Josep Altès (PVB2) i Raimunda Altès (PVB3); mentre que la sèrie narrativa de gravats de $e$ és exactament la mateixa que reprodueixen les impressions de Joan Cetené (PVB4) i Eulàlia Centené (PVB5). A banda de demostrar el gran èxit editorial del Venturós Pelegrí, aquests fets posen de manifest algunes de les pràctiques més comunes entre els professionals de la impremta, que sovint adquirien materials d'èpoques o característiques diverses $\mathrm{i}$ els combinaven en una mateixa edició. També era freqüent emprar els caràcters i les planxes més antics i deteriorats per tirar els fulls volants, els plecs solts i altres productes similars que podríem adscriure a la literatura de canya i cordill.

\section{Cinc edicions del Venturós Pelegrí: descripcions bibliogràfiques}

Tot seguit oferim una descripció de cada una de les cinc edicions incloses al ms. 4504. Segons l'estat actual de la nostra recerca, totes cinc ens han arribat a través d'exemplars únics excepte e, que s'ha conservat en dos testimonis més de la Biblioteca de Catalunya, tal com assenyalarem més avall. Cal notar que quatre de les cinc edicions semblen ser cerverines i setcentistes, tot i que un dels quatre impresos en qüestió podria ser gironí i lleugerament posterior. L'edició que no entraria en aquest grup majoritari és $c$, probablement cinccentista i, sens dubte, la més antiga entre totes les conegudes que transmeten el Pelegrí. Segons la nostra opinió, que exposarem més endavant, $c$ podria ser un volum barceloní més que no pas mallorquí, per bé que tampoc es pot descartar aquesta darrera opció o una altra possibilitat no contemplada per nosaltres.

A les nostres descripcions bibliogràfiques, transcrivim el text fidelment. Mantenim la variació entre els caràcters en majúscula i minúscula, però no distingim entre la lletra rodona i la cursiva, que conviuen en el conjunt de les edicions que ressenyarem. També hem volgut determinar les dimensions d'algunes caplletres $\mathrm{i}$ inicials que són més grans que la resta del text de la pàgina, a través d'una xifra en superíndex que faria correspondre la seua alçada a un nombre determinat de línies impreses. Qualsevol aclariment nostre addicional va indicat entre claudàtors, com esdevé per exemple a l'hora d'introduir la pàgina corresponent al text transcrit o a l'hora d'advertir algunes errates $\mathrm{amb}[\mathrm{sic}]$.

$a$

[P. 3, acèfal:] COMENSA | LO LLIBRE DEL VENTURO[.] | Pelegri. | [Gravat] | P²ER alcansar lo que tant val, | aquell tresor perpetual | de Paradìs, | determinì passar Parìs; | y Lombardìa, | [P. 44, acabament:] la qual demanàm tots dias | pera regnar en Paradìs, y ca ntar [sic] | lo nostre cor, | aixiu fara nostre Senyor, | quins donará assi la gracia, y allá | la Gloria. | Ad quam nos perducat, \&c. | [P. 44, inici:] COBLAS DE LA MORT. | V²EJES mira ma figura, | lletja, vil y sens mesura, | amador home del mon, | y mira jo quina som. | [P. 46, àpode:] esli lletja de mirar, | pensa que tal deus tornar: | Quant com hom aixo ignoras | los jorns, dias ni las horas | [reclam: no] 
Paginació de l'exemplar, acèfal i àpode: [3-46]. Degut al mal estat dels marges del volum, només es veuen guarismes a les pp. [1]0, 11, [1]2, 13-15, 17, 20-21, [2]4, 25, 27-29, 31, 33, 34, 36 i [3]8. Amb reclams. Signatures: $A_{2}, A_{3}, A_{4}, A_{5}$ i $A_{6}$ (a les pp. [3], [9], [11], 17 i [19]). Els gravats conservats a les pp. [3], [5], [6], [8], [1]0, 20 i 33 pertanyen a una sèrie xilogràfica que hem localitzat exactament a les mateixes pàgines d'una altra edició cerverina (PVC1). Hi ha fragments de text il legibles a causa del desgast i pèrdua de bocins de paper. A la figura 1 reproduïm la primera pàgina conservada d'aquest imprès. Únic exemplar localitzat a la Bibliothèque Mazarine, [Ms. 4504, ff. 1-22].

\section{$b$}

[P. 7, acèfal:] los trons me davan espant, y feredat. | A mitxa nit la tempestat se reposá; | y prop de mi senti un Cá fort hudolar, | sentintlo vaigmen despertar tot alterat, | vehentme aixi rodejat de Passions | comenci à dir oracions | ab juntas mans, | pregant à Deu, y à tots los Sants | fossen ab mi: | passat poch temps aprés sentí | fort gemegar, | [P. 42, àpode:] En veurer que pas lo que he contat, | y passaré | fins al dia que guanyaré | lo que mas dat, | germá, perço vesten cuytat, | no perdes temps, | puix te he contat tots los estrems, que jo passi | aquella hora que morí, | y no cregas; | que en lo mon majors penas | [reclam: passás]

Paginació de l'exemplar, acèfal i àpode: 7-42. En alguns folis s'ha perdut un bocí del marge superior, de tal manera que no es veu el guarisme a les pp. [9], 1[3], [18], [29-32] i [41]. Amb reclams. Signatures: B, $B_{2}, C, C_{2}$ (a les pp. [9], 11, 17 i 19). Els gravats conservats a les pp. 8 , 9, 20, 33 i 40 pertanyen a una sèrie xilogràfica que hem localitzat exactament a les mateixes pàgines d'una edició cerverina (PVC2) més una altra sine notis que considerem gironina $(P V G)$. La sèrie de gravats i les portades d'aquestes dues edicions, juntament amb la primera pàgina conservada de $b$, seran reproduïdes sota Mahiques (2016b). Únic exemplar localitzat a la Bibliothèque Mazarine, [Ms. 4504, ff. 23-40].

c

[P. 5, acèfal:] me eren greu, car no vehia anat à | cada pas cahia molt lletjament. | Per qual raho forçadament hagui | à parar y comenci à invocar ma invo- | cada aquella Verge coronada Mare de | Deu? pregant ab temorosa veu nom | [P. 43, acabament:] mateix dia. Preguem à Deu, y Santa | Maria nos fassen obrar virtuts santes | per arribar en la gloria. Lo qual de- | manam cascun dia pera regnar en $\mathrm{Pa}-\mid$ radis, y sanar lo nostre cor, axiu fará | nostre Senyor quins donará assi gracia, | y allá gloria, ad quam nos perducat. | Amen. | [P. 43, inici:] Assi començan las Cobles de la Mort, | ara de nou corregidas. | V ${ }^{4}$ Eges mira ma figura, | Lletja, vil, y sens mesura, | Amador home del mon, | Mira jo quina som. | Vil molt depreciada, y la carn | [P. 44, àpode:] Hont es la gran suptilesa. | De Aristotil home entes Alexandre | Ja no es en loch qui mir sa potencia | Mostrant hont es sa excelencia 
Paginació de l'exemplar, acèfal, àpode i amb altres folis perduts a l'endemig: 5-6, 9-20, 29-40 i 43-44. S'han conservat únicament 14 ff., tot i que, per les característiques del volum, podem suposar que aquesta edició hauria de tenir-ne 24, que és el format més comú, que segueixen gairebé totes les edicions del Venturós amb les Cobles impreses al Principat de Catalunya. Sense reclams. Signatures visibles als folis conservats: $A_{3}, A_{5}, A_{6}, A_{7}, A_{8}, B_{7}\left[\right.$ sic $=B_{1}$ ] (a les pp. 5, 9, 11, 13, 15 i 17). Sèrie narrativa de gravats a les pp. 5, 19 i 32, que reproduïm a les figures 2-4. Hem de suposar que els folis perduts també contenien diverses xilografies. Únic exemplar localitzat a la Bibliothèque Mazarine, [Ms. 4504, ff. 41-54].

\section{$d$}

[P. 1, títol voltat d'orla:] PEREGRINACIó | DEL VENTURóS | PELEGRI, | AB LAS COBLAS DE LA | Mort, ara de nou | corregidas. | [Gravat] | Cervera: En la Estampa de la Ponti- | ficia, y Real Universitat, per | Emmanuel Ibarra. | [P. 2, en blanc] | [P. 3, inici:] COMENSA LO LLIBRE DEL | venturòs Pelegri. | [Gravat] | P²ER alcançar lo que tant val, | aquell tresor perpetual de Paradís, | determiní passar Paris, y Lombardia, | peregrinant ab fantasía de arribar en Roma, | [P. 43, acabament:] la qual demanàm cascun dia | pera regnar | en Paradís, y sanar lo nostre cor, | aixiu farà nostre Senyor, quins donarà | assi la gracia, y alla la Gloria. | Ad quam nos perducat, \&c. | [P. 44, inici:] COBLAS DE LA MORT. | V²Ejes, mira ma figura, | lletja, vil, y sens mesura, | amador home del mon, | y mira jo quina som. | [P. 48, acabament:] llitg sovint, y llitg apart. | Aquestas mias rahons, | llunyat de ocasions, | prega à Deu ab pensa bona | quet guart de la mort segona. Amen. | Ego Fr. Antonius Her, Sanctae | Theologiae Professor, Ordinis Predica- | torum, fateor me legisse praesens opus, | \& illud approbo esse Catholicum. | LAUS DEO.

Paginació: [1-2], 3-48. Amb reclams. Signatures: A, B, B , C i C 2 (a les pp. 3, 9, 11, 17 i 19). Els gravats localitzats a les pp. [1], 3, 5, 6, 8, 9, 20 i 33 pertanyen a una sèrie xilogràfica igualment documentada en altres edicions barcelonines o cerverines (PV1714, PVB2, PVB3 i PVC3). Vegeu sota Mahiques (2015c) una reproducció dels gravats i de les portades d'aquestes edicions, inclosa $d$. Únic exemplar localitzat a la Bibliothèque Mazarine, [Ms. 4504, ff. 70-93].

$e$

[P. 1, títol voltat d'orla:] PEREGRINACIÓ | DEL | VENTURÓS | PELEGRI, | AB LAS | COBLAS DE LA MORT | ara de nou corregidas. | [Gravat] | Cervera: En la Estampa de la Ponti- | ficia, y Real Universitat, per | Manuel Ibarra. | [P. 2, en blanc] | [P. 3, inici:] COMENSA LO LLIBRE | DEL VENTURÓS PELEGRI. | [Gravat] | P²ER alcançar lo que tant val, | aquell tresor perpetual, | de Paradís, | determiní passar París, | [P. 44, acabament:] la qual demanám cascun dia | per regnar en Paradís, y sanar | lo nostre cor, | aixiu fará nostre Seynor, | quins donará assi la gracia, y allá | la Gloria. | Ad quam nos perducat, \&c. | [P. 44, inici:] COBLAS DE LA MORT. | V²Ejes mira ma figura, | lletja, vil, y sens mesura, | amador home del mon, | y mira jo quina som. | [P. 48, acabament:] llig sovin, y llig apart, | Aquestas mias rahons, | llunyat de ocasions, | prega à Deu ab pensa bona | quet guart de la mort segona. Amen. | Ego Fr. Antonius 
Her, Sanctae Theo- | logiae Professor, Ordinis Praedicatorum, fa- | teor me legisse praesens opus, \& illud ap- | prebo [sic] esse Catholicam [sic]. | LAUS DEO.

Paginació: [1-2], 3-48. Amb reclams. Signatures: $A_{2}, A_{3}, A_{4}, A_{5}$ i $A_{6}$ (a les pp. 3, 9, 11, 17 i 19). Els gravats conservats a les pp. 3, 5, 6, 8, 10, 20 i 33 es corresponen a la sèrie xilogràfica que hem localitzat exactament a les mateixes pàgines de dues edicions barcelonines (PVB4 $\mathrm{i}$ PVB5). Mahiques (2015c) reprodueix els gravats i les portades de PVB4, PVB5 i e, aquesta darrera a partir d'un exemplar de la Biblioteca de Catalunya, [VI-I-C 8/13]. Podria referirse a aquesta edició la següent descripció bibliogràfica de Marcet/Solà (1998: 283a): «s. a. Peregrinació / del venturós / pelegri, / ab las / coblas de la mort / ara de nou corregidas. / Cervera: En la Estampa de la Ponti- / ficia, y Real Universitat per / Manuel Ibarra.- 14 cm, 14 p.». Exemplars localitzats: Biblioteca de Catalunya, [VI-I-C 8/13] [VI-I-C 8/16]; Bibliothèque Mazarine, [Ms. 4504, ff. 93 ${ }^{\text {bis }+94-116] . ~}$

\section{Anàlisi de les dades bibliogràfiques}

L'anàlisi de les cinc edicions ens permet remarcar diversos aspectes relatius a la producció, difusió i conservació del Pelegríi les Cobles. Salta a la vista l'extrema raresa d'aquestes edicions, sobretot les que són acèfales i àpodes $(a, b i c)$. De fet, coincideix que el text d'aquells impresos que s'han conservat en més mal estat no es pot restituir a través d'altres exemplars, perquè no se n’ha localitzat cap més.

És també ben interessant fixar-se en les sèries xilogràfiques que il lustren cada una de les edicions. Tal com hem indicat, $a$ reprodueix exactament els mateixos gravats que trobem a PVC1, tot i que les edicions són diferents, mentre que $b$ reutilitza les mateixes planxes que localitzem tant en $P V C 2$ com en $P V G$. Això ens porta a concloure que $a$ i $b$ són ben probablement edicions cerverines, igual que $d$ i $e$, aquesta darrera també coneguda a través d'altres exemplars.

L'imprès més important des del punt de vista bibliogràfic i filològic, i també el que més problemes planteja, és $c$, del qual només resten 14 ff. (= [41-54] del ms. 4504). La part conservada inclou tres xilografies, reproduïdes a les figures 2-4, que no hem aconseguit documentar ni en cap altra edició del Pelegríni tampoc a la resta de la producció gràfica que hem revisat expressament amb la finalitat de determinar el taller o si més no el lloc i l'època de $c$. S'han de destacar algunes particularitats que diferencien els gravats d'aquesta edició respecte de les nombroses i successives reimpressions setcentistes del Pelegrí. Tal com es pot observar a través de la comparació dels facsímils que reproduïm al final d'aquest article, la figura $2(c$, p. 5) presenta alguns trets específics de la distribució de l'espai iconogràfic, com són els núvols a la part superior i el mar amb vaixells a l'esquerra, bastant infreqüents al corpus d'edicions dels segles XVIII-XIX que hem pogut consultar. ${ }^{6}$

6 A banda del cas que estem comentant, s'adiuen a aquest mateix esquema iconogràfic quatre gravats reproduïts per Mahiques (2015b, fig. 5; 2015c, fig. 4; 2016c, fig. 2 i 9). Els dos primers són documentats als segles XVIII-XIX, per una banda a Barcelona i Lleida (PVB1 i PVL) i per altra banda a Barcelona i Cervera (PV1714, PVC4, PVC5 i PVC6); els dos darrers a la Barcelona del segle XVII (l'un a PV1635 i PV1677;

SCRIPTA, Revista internacional de literatura i cultura medieval i moderna, núm. 5 / juny 2015 / pp. 122 - 138 ISSN: $2340-4841 \cdot$ doi:10.7203/SCRIPTA.5.6378 
La figura 3 (c, p. 19) mostra a la part superior un àngel que sosté una llegenda impresa: «Memento mori». A sota, diríem que giren el cap i llegeixen aquesta sentència llatina dos personatges, per una banda un esquelet que surt del seu taüt i per una altra banda un jove encara viu que sembla nuu. No hem aconseguit documentar cap altre testimoni acord a aquest mateix pla iconogràfic, que només en part podria comparar-se amb les xilografies estudiades per Morreale (1973-1974) en relació amb el tema de la trobada dels tres vius i els tres difunts, o amb algunes pintures estudiades i reproduides per Valdivieso (2002: 22, 37-51 i 78). Un dels aspectes analitzats per aquest darrer estudiós és la imatge de l'àngel admonitor del desengany del món, funció que trobem representada, sens dubte, en el gravat del Pelegrí que ara ens ocupa. Cal advertir que l'escenografia d'aquesta xilografia és substituïda a la major part de les edicions d'aquesta obra per una altra caracterització diferent on la Mort aguaita a la vora del llit on dorm el protagonista. ${ }^{7}$ Aquestes dues modalitats il lustren el mateix passatge i se situen, doncs, exactament en el mateix punt de la trama narrativa del Venturós.

La figura 4 (c, p. 32) respon a un model iconogràfic infreqüent a partir del segle XVIII, ja que des d'aleshores el judici particular del difunt amb qui parla el Venturós Pelegrí sol escenificar l'àngel dempeus, amb una mà enllaçada a l'ànima difunta, i sovint (tot i que no sempre) amb l'altra mà amb l'espasa enlairada, disposat a defendre la persona processada. En canvi, l'àngel de la figura 4 es troba suspès enlaire just al capdamunt de l'ànima difunta, petita i en posició de pregària. També són ben notables les diferències estilístiques relatives al disseny del diable, que té una aparença molt més monstruosa als testimonis més antics. ${ }^{8}$

Un dels trets més destacats de $c$ és el fet de disposar els versos a línia seguida, com a les edicions mallorquines dels segles XVII-XVIII que ens han arribat, però es distingeix d'aquestes pel fet d'incorporar les Cobles de la Mort. ${ }^{9}$ De més a més, la distribució del text i dels gravats s'adiu

l'altre a PV1683).

7 Aquesta darrera escena constitueix un patró comú documentat a les sèries estudiades per Mahiques (2014; 2015a; 2015b; 2015c; 2016b; 2016c).

8 La figura 4 correspon a un model iconogràfic que segueixen igualment tres gravats documentats al segle XVII, cada un d'ells en una edició diferent (PV1635, PV1683 i PV1697). El mateix patró reapareix durant la centúria següent en una altra xilografia reimpresa en diverses ocasions (PV1714, PVC4; i amb la figura del diable totalment mutilada i expurgada a l'únic exemplar conegut, PVC5). De tota manera, tal com hem indicat, aquesta representació és infreqüent als segles XVIII-XIX. De fet, segons l'estat actual de la nostra recerca, podem considerar que el darrer tipògraf en utilizar aquest model és Manuel Ibarra, mort el 1757. Com a mostra gràfica d'aquests comentaris nostres, remetem a les figures reproduïdes per Mahiques (2016c; 2015c).

9 Entre les edicions mallorquines, hem revisat directament PV1697 i PVPM, ambdues amb el text a línea seguida, que transmeten la Peregrinació sense les Cobles, però en el segon cas amb altres dues obres en versos castellans. A banda d'una edició de 1697 que cal identificar amb PV1697, Bover (1868: 665) n'esmenta una altra de 1666 que no hem localitzat, i una altra edició de Pere Capó, de 1754, que Bover (2001: 199-200, 
perfectament amb la pauta més comuna, que trobem amb lleugeres variacions en la major part de les edicions del Principat, sobretot les més antigues. Aquesta particularitat es pot demostrar a partir de la comparació de les figures 2-4 amb altres edicions del Pelegrí, on es fa constatar com diversos gravats sobre el mateix motiu ocupen la mateixa página $-\mathrm{o}$ si no, la pàgina anterior o la posteriortant en $c$ com en vàries edicions de Barcelona, Cervera o altres nuclis urbans catalans. Aquesta tendència no es pot estendre a PV1697 i PVPM, les dues úniques edicions mallorquines que hem pogut consultar íntegrament, on es dilueix la seqüenciació de la sèrie de gravats i també manquen les Cobles. Aquestes característiques ens plantegen un dilema: caldria assignar $c$ preferentment a una impremta barcelonina, o a una mallorquina? Sense excloure altres possibilitats, hem decidit indagar aquestes dues vies, amb uns resultats que, certament, hem de considerar del tot insatisfactoris, car no hem trobat cap indici concret que ens permeta arribar a cap conclusió mínimament precisa.

Només podem dir que $c$ ha de ser una edició antiga, nosaltres creiem que de mitjan segle XVI, tot i que podria ser també una miqueta posterior. Fins i tot podria tractar-se d'una edició de l'inici del Siscents, però en aquest supòsit els materials d'impremta utilitzats haurien de ser de la centúria anterior i molt vells. Vista la raresa dels gravats, que tal com hem dit no hem localitzat en cap altra edició, ni del Venturós ni de cap altra obra, hem arribat a pensar que $c$ hauria pogut ser una edició deguda a un tipògraf que no s'ha de comptar entre els més prolífics de l'època, o que estava establert en una ciutat sense la importància ni el volum editorial de Barcelona o València. Aquestes suposicions són, però, del tot provisionals i es fonamenten bàsicament en una manca de resultats que podria denotar una producció més aviat modesta de l'impressor, o bé una circulació marginal de l'obra estampada, amb matrius i materials tipogràfics difícilment localitzables a hores d'ara. Podria tractar-se d'una edició mallorquina? Encara que sense un fonament prou sòlid, l'anàlisi tipobibliogràfica que hem realitzat ens inclina a pensar que aquesta edició no fou impresa pel llinatge dels Guasp, la qual cosa reduiria considerablement la possibilitat que aquesta edició fos mallorquina. ${ }^{10}$ Per altra banda, alguns documents de l'Arxiu Històric de Protocols de Barcelona demostren clarament l'existència d'edicions cinccentistes del Pelegrí que no semblen haver perviscut

núm. 212) descriu amb més detall a partir d'un exemplar pertanyent a una col lecció privada. D'aquesta notícia deduïm que l'edició en qüestió no incloïa les Cobles de la Mort, la qual cosa podria induir a pensar que el Venturós a Palma de Mallorca s'imprimí sempre al marge de les Cobles. Si això fos així, s'hauria de descartar una eventual adscripció mallorquina de $c$. Sobre la difusió impresa del Pelegrí a les Balears, vegeu també Sabater (1985: 76) i Llompart (1989: 7, núm. 262, «Item setze Pelegrins»). Aquesta darrera notícia es refereix a l'inventari, datat de 4 d'agost de 1634, dels béns que Jaume Guasp heretà del seu pare Gabriel Guasp. A la nota 11 donem una altra referència insular al Pelegrí, de l'any 1588.

10 Tot i que aquesta família d'impressors no tenia el monopoli absolut a Mallorca, era sens dubte el taller més actiu, del qual en conservem una producció molt major que la de qualsevol altre tipògraf que treballés a l'illa durant els segles XVI-XVIII. Hem analitzat a fons els catàlegs d'elements ornamentals que van pertànyer a aquesta família d'impressors (Guasp 1950), i també nombroses edicions que hem consultat en diverses biblioteques o a través de còpies digitals accessibles. Sobre la trajectòria d'aquesta família i, més en general, sobre la impremta a les Illes Balears, remetem a la bibliografia esmentada a la nota anterior.

SCRIPTA, Revista internacional de literatura i cultura medieval i moderna, núm. 5 / juny 2015 / pp. 122 - 138 ISSN: 2340-4841 · doi:10.7203/SCRIPTA.5.6378 
fins al dia d'avui, dada que manté en peu la hipòtesi de l'adscripció barcelonina de $c{ }^{11}$

Certament, el coneixement de la data i el lloc de publicació de $c$ podria esclarir enormement la història de la transmissió impresa del Pelegríi les Cobles, tot perfilant de manera més clara les relacions entre les branques barcelonina i mallorquina. De moment, però, aquests dubtes romanen encara per resoldre, i només podem dir que $c$ és imprès a línia seguida com als impresos mallorquins que coneixem; i incorpora les Cobles com esdevé a la gran branca d'edicions barcelonines i de la resta del Principat de Catalunya. Deixades de banda aquestes qüestions, la troballa de $c$ aporta dades fonamentals per a l'establiment d'una edició crítica del Venturós, perquè constitueix el testimoni més antic conservat i, de més a més, demostra l'antiguitat de dos aspectes fonamentals: per una banda, la disposició del text a línia seguida; per altra banda, la difusió conjunta del Pelegrí i les Cobles.

\section{Conclusions}

Devem a Josep Tastu (1787-1849) la recopilació dels materials continguts al ms. 4504 de la Bibliothèque Mazarine de París, on s'inclouen testimonis impresos i manuscrits de la «Peregrinació del Venturós Pelegrí» ab les «Cobles de la Mort». Les cinc edicions inserides en aquest manuscrit factici destaquen per la seua raresa, com demostra el fet que només una d'elles ens resulte coneguda a través de diversos exemplars.

Quatre dels cinc impresos podrien haver estat estampats a Cervera, tot i que per a un d'aquests s'hauria d'afegir, com a segona hipòtesi probable, el seu origen gironí. El cas més interessant i enigmàtic afecta un exemplar acèfal i àpode que deu datar de mitjan segle XVI o una mica més tard, sense anar més enllà de la primera dècada del Siscents, etapa en què només trobem notícies indirectes i indicis sobre la publicació del Pelegrí a Barcelona i a Palma de Mallorca. L'exemplar en qüestió, identificat sota la sigla $c$, és el testimoni més antic del Venturós, aspecte que li atorga un interès especial no només per a l'establiment d'una edició crítica d'aquesta obra sinó també de cara al coneixement de les seues vies de difusió, tot dilucidant com el text imprès i la imatge gràfica es relacionen mútuament i evolucionen al llarg de l'Edat Moderna.

11 Devem a la gentilesa de Rosa Nacente les dades que tot seguit exposarem, extretes de documents de l'Arxiu Històric de Protocols de Barcelona. El testament de Francí Joan Cabrit, datat de 9 de març de 1563, inclou un inventari de llibres on indica: «Item, sinch raymes de paper blanch del Palagrí [...] Ítem, una rayma paper blanch del Pelegrí [...] Ítem, sinch dotzenas de Palagrins. Ítem, vint y dos Basarolas de p. grans. Ítem, altras vint Palagrins». L'inventari de béns d'Hubert Gotard, fet a instàncies de la seua vídua, Maria Gotard, de l'11 al 17 de maig de 1590, especifica de la mateixa manera: «Item, dos raymes de Pelegrins [...] Ítem, quatre raymas de Pelegrins». Finalment, al memorial dels llibres d'Onofre Gori venuts per la seua vídua, localitzat en l'any 1595 del registre de Galceran Francesc Devesa (510/8), consten «8 Pelegrins». Per tant, Barcelona fou un focus important en la difusió del Venturós Pelegrí durant la segona meitat del segle XVI. De tota manera, la primera notícia que coneixem d'aquesta obra lligada a l'àmbit mallorquí remunta igualment a una data bastant reculada, concretament a l'inventari de béns de Bartomeu Vives datat de l'any 1588 (Llompart 1996: 206, núm. 25, «Item quatre llibres del Pelegrí y uns Vesprals»). Per tant, l'adscripció de $c$ a Barcelona o a Palma de Mallorca seria igualment probable a la llum de la documentació que ens ha arribat.

SCRIPTA, Revista internacional de literatura i cultura medieval i moderna, núm. 5 / juny 2015 / pp. 122 - 138 ISSN: $2340-4841 \cdot$ doi:10.7203/SCRIPTA.5.6378 
Joan Mahiques Climent. Cinc edicions del Venturós Pelegrí a la Bibliothèque Mazarine de París

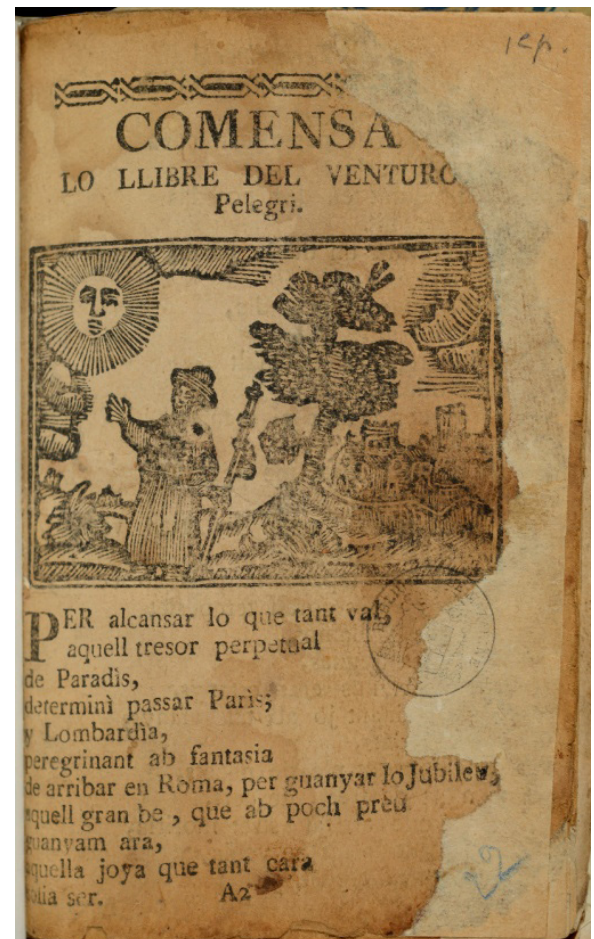

Figura 1

a, p. [3]

Bibliothèque Mazarine, [Ms. 4504]

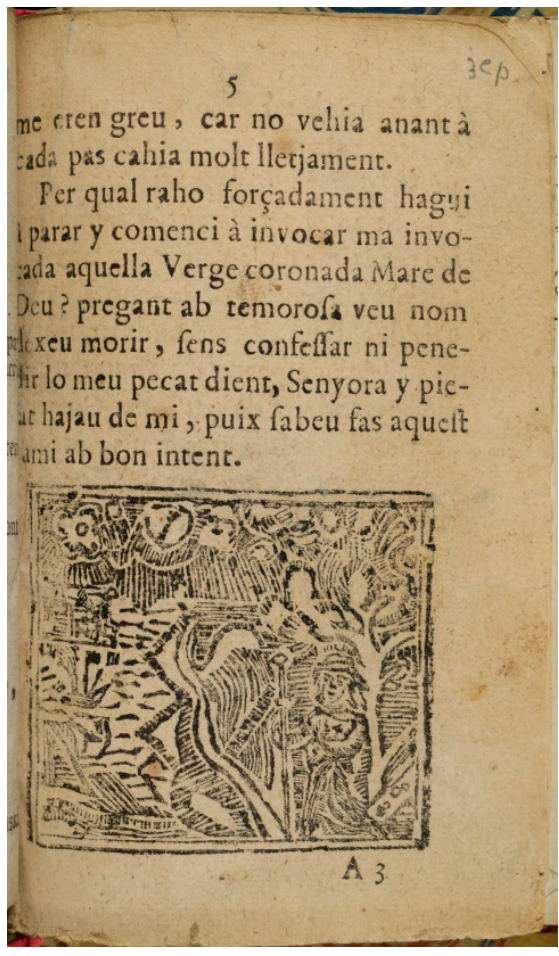

Figura 2

c, p. 5

Bibliothèque Mazarine, [Ms. 4504] 
Joan Mahiques Climent. Cinc edicions del Venturós Pelegrí a la Bibliothèque Mazarine de París

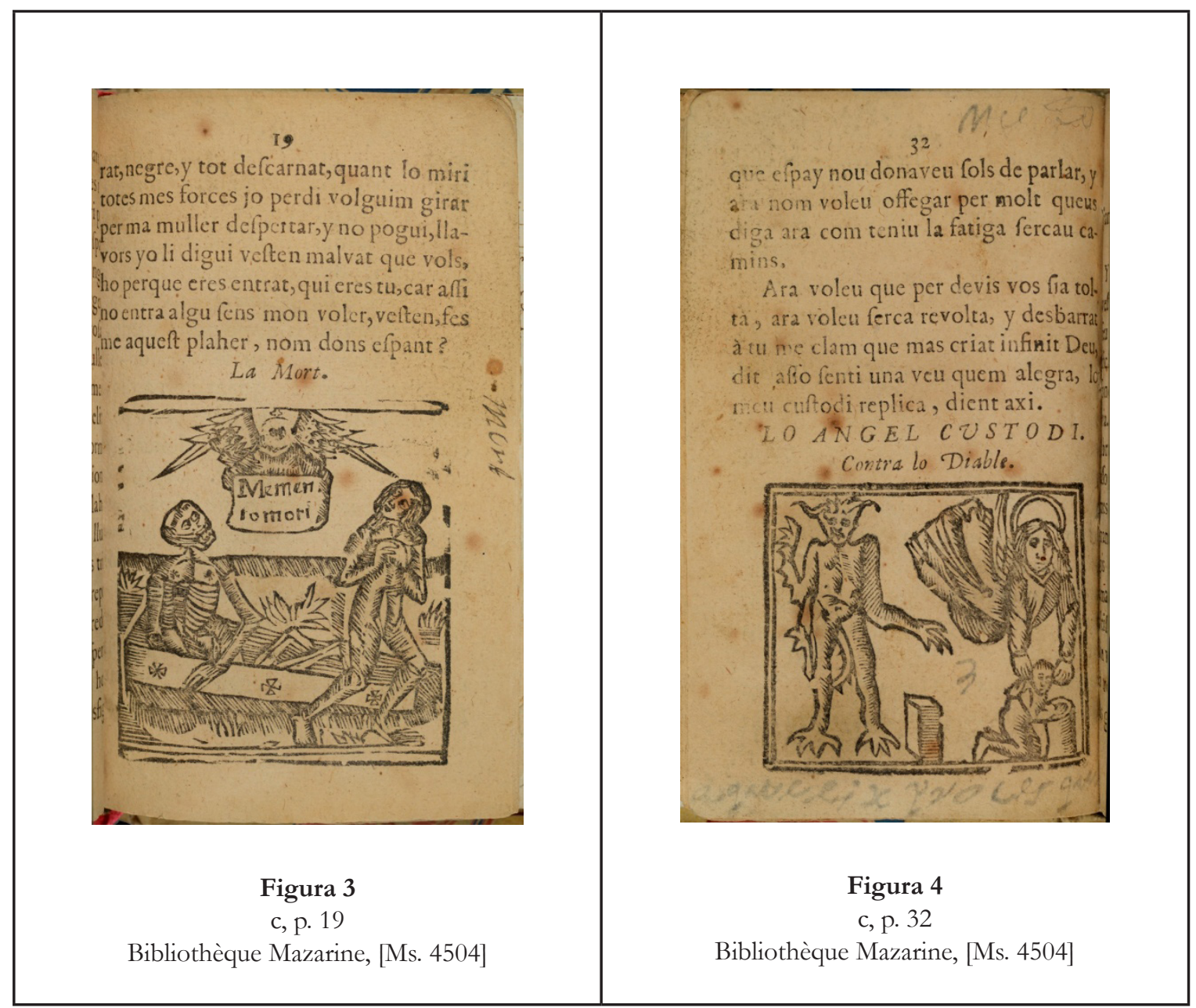

SCRIPTA, Revista internacional de literatura i cultura medieval i moderna, núm. 5 / juny 2015 / pp. 122 - 138 ISSN: 2340-4841 $\cdot$ doi:10.7203/SCRIPTA.5.6378 


\section{Bibliografia crítica}

Bover, Jaume (2001) Els Capó, impressors de Mallorca. Segles XVII-XVIII. Història i cataleg, Palma de Mallorca, Institut d'Estudis Baleàrics.

Bover, Joaquim Maria (1868) Biblioteca de escritores baleares, Palma de Mallorca, P.J. Gelabert, vol. 1.

Burgos Rincón, Francisco Javier (1997) «Privilegios de imprenta y crisis gremial. La imprenta y librería barcelonesa ante el privilegio de impresión de los libros de enseñanza dela Universidad de Cervera», Estudis històrics $i$ documents dels arxius de protocols, 15, pp. 257-298.

Guasp Pou, Felipe (pròl.) (1950) Colección de 1440 xilografias (iconográficas, heráldicas, tipográficas, históricas, dod existentes en los obradores de la Imprenta y Librería de Guasp, Palma de Mallorca, Guasp, 5 vol. [1-4: 1440 xilografies; «Apéndice»: 115 xilografies].

Llanas, Manuel (2003) L'edició a Catalunya: el segle XVIII. Amb la col taboració de Montse Ayats, Barcelona, Gremi d'Editors de Catalunya.

Llompart, Gabriel (1989) La imprenta i llibreria de Gabriel Guasp a 1634 (amb la bibliografia científica de l'autor 1945-1988), Palma de Mallorca, Quaderns de Ca la Gran Cristiana.

(1996) «Botiguers i quincallaires a la pagesia de la Mallorca medieval», Bolletí de la Societat Arqueologica Lul liana, 52, pp. 179-208.

Mahiques Climent, Joan (2013) «Dos glosas de romances castellanos en el ms. 4495 de la Bibliothèque Mazarine de París», Revista de filología española, 93/2, pp. 291-312.

- (2014) «La Peregrinació del Venturós Pelegrí ab les 'Cobles de la Mort': una sèrie de gravats en set edicions cerverines no datades», Zeitschrift für Katalanistik, 27, pp. 189-206.

- (2015a) «La Peregrinació del Venturós Pelegrí' ab les 'Cobles de la Mort': una sèrie de gravats en setze edicions cerverines (circa 1730-1804)», Caplletra, 58, en premsa.

$\square$ (2015b) «Notes sobre la difusió impresa del Venturós Pelegrí als segle XVIII-XIX. Tres edicions barcelonines més una altra impresa a Lleida», BiD. Textos universitaris de biblioteconomia i documentació, 34, en premsa.

—. (2015c) «Notes sobre la difusió impresa del Venturós Pelegrí als segle XVIII-XIX. Sèries de gravats impreses a Barcelona, Cervera i Manresa», Bulletin of Hispanic Studies, en premsa.

—_. (2016a) «Sobre la difusió de les Cobles de la Mort al segle XVI». [Enviat a una revista].

—. (2016b) «Edicions del Venturós Pelegrí amb sèries de gravats impreses a Cervera i Girona». [Enviat a una revista].

—. (2016c) «Edicions del Venturós Pelegrí impreses a Barcelona al segle XVII». [Enviat a una revista].

Marcet i Salom, Pere / Solà, Joan (1998) Història de la lingüística catalana: 1775-1900. Repertori crític, Vic / Girona, Eumo / Universitat de Vic / Universitat de Girona, vol. 1. 
[Massó i Torrents, Jaume] (1902) «Papers de Josep Tastu (1787-1849) existents avui en la 'Bibliothèque Mazarine' de París», Revista de Bibliografia Catalana, 2, pp. 140-155.

MCEM (2014). Eulàlia Duran (dir.) / Maria Toldrà (coord.), MCEM (Base de dades de Manuscrits Catalans de l'Edat Moderna), Barcelona, Institut d'Estudis Catalans <http://mcem.iec.cat/>. Data de consulta: 05/06/2014.

Molinier, Auguste (1892-[1898]) Catalogue des manuscrits de la Bibliothèque Mazarine. Tome quatrième, París, Librairie Plon. [Al final s’afegeix un «Supplément. 1898», que descriu els ms. 4495-4528 de la Bibliothèque Mazarine].

Morreale, Margherita (1973-1974) «Un tema no documentado en España: el 'Encuentro de los tres vivos y los tres muertos'», Boletín de la Real Academia de Buenas Letras de Barcelona, 35, pp. 257-263.

Pagès, Amédée (1888) «Notice sur la vie et les travaux de Joseph Tastu», Revne des Langues Romanes, 32 , pp. 57-76 i $127-145$.

Sabater, Gaspar (1985) La imprenta y las xilografías de los Guasp, Palma de Mallorca, Institut d'Estudis Baleàrics.

Valdivieso, Enrique (2002) Vanidades y desengaños en la pintura española del Siglo de Oro, Madrid, Fundación de Apoyo a la Historia del Arte Hispánico.

Verrié i Faget, Jordi (1981) Continuitat pedagògica catalana durant els segles XVIII i XIX, Barcelona, Grup Promotor d'Ensenyament i Difusió del Català.

Edicions citades de la Peregrinació del Venturós Pelegrí

a. [«eregrinació del Venturós Pelegrí ab les «Cobles de la Mort». Cervera: Estampa de la Pontifícia i Real Universitat, segles XVIII-XIX]. Únic exemplar localitzat, acèfal i àpode: Bibliothèque Mazarine, [Ms.4504, ff. 1-22].

b. [«Peregrinació del Venturós Pelegrí ab les «Cobles de la MorŁ. ¿Cervera: Manuel Ibarra, 17351757?; o bé: ¿Girona: Impremta de Bro o successors, segles XVIII-XIX?]. Únic exemplar localitzat, acèfal i àpode: Bibliothèque Mazarine, [Ms. 4504, ff. 23-40].

c. [«Peregrinació del Venturós Pelegrí» ab les «Cobles de la Mort». ¿2a meitat segle XVI?]. Únic exemplar localitzat, acèfal i àpode: Bibliothèque Mazarine, [Ms. 4504, ff. 41-54].

d. «PEREGRINACIó | DEL VENTURóS | PELEGRI, | AB LAS COBLAS DE LA | Mort, ara de nou | corregidas.». Cervera: Emmanuel Ibarra, [1735-1757]. Únic exemplar localitzat: Bibliothèque Mazarine, [Ms. 4504, ff. 70-93].

e. «PEREGRINACIÓ | DEL | VENTURÓS | PELEGRI, | AB LAS | COBLAS DE LA MORT | ara de nou corregidas.». Cervera: Manuel Ibarra, [1735-1757]. Exemplars: Bibliothèque Mazarine, [Ms. 4504, ff. 93 ${ }^{\text {bis }}+94-116$ ]; Biblioteca de Catalunya, [VI-I-C 8/13] [VI-I-C 8/16]. 
Joan Mahiques Climent. Cinc edicions del Venturós Pelegrí a la Bibliothèque Mazarine de París

PV1635. «PEREGRINACIO | DEL VENTV- | ROS PELEGRI.». Barcelona: Sebastià i Jaume Mathevat, 1635. Únic exemplar localitzat: Public Library of New York, [Spencer Coll. Span. 1635].

PV1677. «PEREGRINACIO | DEL VENTVROS | PELEGRI.». Barcelona: Estampa de Mathevat administrada per Marti Gelabert, 1677. Únic exemplar localitzat: Biblioteca de Catalunya, [6-I-7/1].

PV1683. «PEREGRINA- | CIO DEL VENTV- | ROS PELEGRI.». Barcelona: Antoni Lacavalleria, 1683. Únic exemplar localitzat: Biblioteca de Catalunya, [6-I-C 7/2].

PV1697. «PAREGRINACIO | DEL VENTVROS | PALEGRI, | Y DE LO QVE LI SEGVI | EN LA SVA IORNADE.». Palma de Mallorca: Melchior Guasp, 1697. Exemplars: Biblioteca Nacional de España, [R/11151]; Biblioteca del Monestir de la Real de Palma de Mallorca, [BB-4525].

PV1714. «PEREGRINACIÓ | DEL VENTVRÓS | PELEGRI.». Barcelona: Rafel Figueró, 1714. Únic exemplar localitzat a la Biblioteca de Catalunya, [15-I- 104/16].

PVB1. «PEREGRINACIO | DEL VENTUROS | PELEGRI.». Barcelona: Rafel Figueró, [1726 ad quem]. Exemplars: Biblioteca de Catalunya, [VI-I-C 8/5]; Biblioteca de l'Abadia de Santa Maria de Poblet, [C.12º-F.2-19-1/12].

PVB2. «PEREGRINACIò | DEL VENTUROS | PELEGRI | AB LAS COBLAS DE LA | Mort ara de nou corregidas.». Barcelona: Joseph Altès, [1772 ad quem]. Únic exemplar localitzat a la Biblioteca de Catalunya, [VI-I C8/1].

PVB3. «PEREGRINACIò | DEL VENTUROS | PELEGRI | AB LAS COBLAS DE LA | Mort ara de nou corregidas.». Barcelona: Raymunda Altès, [1790 ad quem]. Únic exemplar localitzat a la Biblioteca de Catalunya, [VI-I C8/2].

PVB4. «PEREGRINACIÓ | DEL | VENTURÓS | PELEGRI, | AB LAS | COBLAS DE LA MORT, | ara de nou corregidas.». Barcelona: Joan Centené, [1798 ad quem]. Exemplars: Biblioteca de Catalunya, [VI-I-C 8/4]; Biblioteca de la Casa de Alba, [3672].

PVB5. «PEREGRINACIO | DEL | VENTUROS | PELEGRI, | AB LAS | COBLAS DE LA MORT, | ara de nou corregidas.». Barcelona: Eulàlia Centené, [¿circa 1800?]. Únic exemplar localitzat: Biblioteca de Catalunya, [VI-I-C 8/3].

PVC1. «PEREGRINACIO | DEL | VENTUROS | PELEGRI, | AB LAS | COBLAS DE LA MORT | ARA DE NOU | CORREGIDAS.». Cervera: Estampa Pontifícia i Real Universitat, [segles XVIII-XIX]. Únic exemplar localitzat: Bibliothèque Nationale de France, [YG 2785].

PVC2. «PEREGRINACIÓ | DEL VENTURÓS | PELEGRÍ | AB LAS COBLAS DE LA MORT, | ARA DE NOU CORREGIDAS.». Cervera: Emanuel Ibarra, [1735-1757]. Exemplars: Biblioteca del Cercle de Lectura de Reus, [833.5«S» Per-12] [833.5«V» Per12] (2 topogràfics, però 4 exemplars); Arxiu Comarcal de la Segarra, [R.867]; Arxiu de la Corona d'Aragó, [27 /5/26]; Biblioteca de l'Abadia de Santa Maria de Poblet, [849F242]; Biblioteca de la Universitat d'Alacant, [FL FA/253]; Biblioteca Pública Episcopal del Seminari de Barcelona, [849.9 Per Reg. 10735]. 
PVC3. «PEREGRINACIÓ | DEL VENTURóS | PELEGRI, | AB LAS COBLAS DE LA | Mort, ara de nou | corregidas.». Cervera: Emmanuel Ibarra, [1735-1757]. Únic exemplar localitzat: Biblioteca de l'Abadia de Santa Maria de Poblet, [Reg. 16284, Sig. RE11].

PVC4. «PEREGRINACIó | DEL VENTURóS | PELEGRI | AB LAS COBLAS DE LA | Mort ara de nou corregidas.». Cervera: Emmanuel Ibarra, [1735-1757]. Únic exemplar localitzat: Biblioteca de la Universitat Pompeu Fabra, [IUHJVV - Res C: ZX1740z.P47].

PVC5. «PEREGRINACIó | DEL VENTURóS | PELEGRI | AB LAS COBLAS DE LA | Mort ara de nou corregidas.». Cervera: Emmanuel Ibarra, [1735-1757]. Únic exemplar localitzat: Biblioteca de Catalunya, [82-12-C 16/20].

PVC6. «PEREGRINACIÓ | DEL | VENTURÓS | PELEGRI, | AB LAS | COBLAS DE LA MORT, | ara de nou corregidas.». Cervera: Emanuel Ibarra, [1735-1757]. Exemplars localitzats: Arxiu Comarcal de la Segarra [Impremta de la Universitat reg. 160]; Biblioteca de Catalunya, [I-Verrié 881/15-12].

PVG. «PEREGRINACIÓ | DEL VENTURòS | PELEGRI, | AB LAS COBLAS DE | la Mort, ara de nou | corregidas.». [Girona: ¿Josep Bro o successors?, segles XVIII-XIX]. Únic exemplar localitzat a la Biblioteca del Seminari de Girona, [06/856]

PVL. «PEREGRINACIÓ | DEL VENTUROS | PELEGRI | AB LAS COPLAS DE | la mort, ara de nou | corregidas.». Lleida: Bonaventura Corominas, [circa 1840]. Exemplars: Biblioteca de Catalunya, [16-III-10/7] [15-IV-53/1] [16-III-11/39] [16-III-11/32] [11V-6]; Biblioteca Museu Víctor Balaguer, [F849.9/433]; Biblioteca de l'Abadia de Santa Maria de Poblet, [849F241]; Biblioteca de la Universitat de Lleida, [R. Sol i C. Torres COR-3/0044] [R. Sol i C. Torres COR-4/0023]; Biblioteca de l'Institut d'Estudis Ilerdencs, [X-4-48 R.2271-ARE] [V(B)-2 C.36/26 R.1058-TAR].

PVPM. «EL VENTUROS | PELEGRI, | Y DE LO QUE ANANT A | Roma li succeí.». [Palma de Mallorca, ¿2a meitat del segle XVIII?]. Únic exemplar localitzat: Biblioteca Lluís Alemany, [U-2 (110)/22]. 